\title{
With Or Without Rutabaga?
}

\author{
Gary Brunswick, Northern Michigan University, USA
}

\begin{abstract}
The case involves a small local business (family-owned) which produces and sells an interesting food product-the pasty. The business is quite profitable, and potential growth options are contemplated, including but not limited to geographic expansion, online sales, focus on developing brand equity, product line extension, or maintaining the status quo.
\end{abstract}

Keywords: Small Business Expansion; Food Marketing, Geographic Expansion; Online Distribution and Marketing; Product Line Extension; Brand Equity

\section{INTRODUCTION}

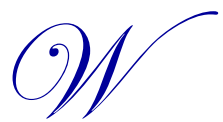
ith or without?" After he said it, Toivo Maki was thinking about how many times he had asked that question since the opening of his family business many years ago - The Pasty King (or TPK, LLC.) Maybe a million times over the past 20 years? Toivo was the current president of TPK, LLC, and was proud of his family's business and high-level of product quality. Many locals and even non-locals were loyal to TPK's version of the pasty, sometimes placing large orders (10 or more pasties).

The customer that Toivo was just talking to was a regular customer, and "with or without" was a standard greeting for many of his regulars - what he was referring to was whether or not they wanted their pasty with or without rutabaga, which represented the two basic versions of the pasty sold by his family's little shop, located in Marquette, Michigan. Some regular customers had a strong preference, and always ordered the same pasty, while others would switch their preferences periodically, so Toivo could never really predict.

After that regular customer walked out of the front door, Toivo was again back to what he had been thinking about lately - namely what the future will hold for his family business. Sales have been strong for years now, but is more growth possible for TPK LLC., and if so, how can such growth be achieved? Although the business is located in a small town in the Upper Peninsula of Michigan, Toivo has seen a number of examples of local business that have expanded by adding multiple locations (even outside of the state of Michigan). Or, should TPK start thinking about online sales, which would have a much broader reach, but would also bring order fulfillment challenges? Perhaps the product is too localized in order to reach a broader audience via an online channel of distribution? Should more of a regional or national branding strategy be pursued, with the goal of actually selling TPK to a larger food company, who would have the financial resources and the marketing experience to take the brand nationally? Should more variations of the basic pasty be introduced? Or, should Toivo just be happy with the small, successful business he and his family has developed, and leave well enough alone? Maybe other growth options exist that Toivo hadn't thought of yet? Toivo popped a pasty nugget (a smaller bit-sized version of a pasty, recently developed by TPK) in his mouth and headed for the kitchen to supervise the day's pasty production, still thinking about the future and what TPK should do.

\section{The History of the Pasty}

The pasty has a long and interesting history, not just in the Upper Peninsula of Michigan, but also in other parts of the world. The word "pasty" has a specific pronunciation (rhymes with "nasty", not with "tasty") and Toivo could immediately tell if a customer was a local or a non-local (tourist) simply by their pronunciation of the word. Taken from Wikipedia, here is a brief history of the pasty: 
A pasty (/'pasti/, Cornish: Pasti) is a baked pastry, a traditional variety of which is particularly associated with Cornwall, England, United Kingdom. It is made by placing an uncooked filling, typically meat and vegetables, on one half of a flat shortcrust pastry circle, folding the pastry in half to wrap the filling in a semicircle and crimping the curved edge to form a seal before baking.

The pasty is now popular worldwide due to the spread of Cornish miners, and variations can be found in Australia, the United States, Argentina, Mexico, Ulster and elsewhere.

The pasty is regarded as the national dish of Cornwall, and the term "Cornish pasty" has been in use since at least the early 1860s., In recent years, the pasty still is a popular food in Wales, generating about 6\% of the food economy in Cornwall (the area considered to be the home of the pasty).

A traditional Cornish pasty is filled with steak and vegetables. The recipe for a Cornish pasty, as defined by its protected status, includes diced or minced beef, onion, potato and swede in rough chunks along with some "light peppery" seasoning. The cut of beef used is generally skirt steak. Swede is sometimes called turnip in Cornwall, but the recipe requires use of actual swede, not turnip. Pasty ingredients are usually seasoned with salt and pepper, depending on individual taste. The use of carrot in a traditional Cornish pasty is frowned upon, though it does appear regularly in recipes.

Migrating Cornish miners and their families (colloquially known as Cousin Jacks and Cousin Jennies) helped to spread pasties into the rest of the world during the 19th century. As tin mining in Cornwall began to decline, miners took their expertise and traditions to new mining regions around the world. As a result, pasties can be found in many regions, including:

Many parts of Australia, including the Yorke Peninsula, which has been the site of an annual pasty festival (claimed to be the world's largest) since 1973. A clarification of the Protected Geographical Status ruling has confirmed that pasties made in Australia are still allowed to be called "Cornish Pasties".

Pasties can be found in California and Nevada in many historical Gold Rush towns, such as Grass Valley and Nevada City.

Within the Upper Peninsula of Michigan, in some areas, pasties are a significant tourist attraction, including an annual Pasty Fest in Calumet, Michigan in late June. Pasties in the Upper Peninsula of Michigan have a particularly unusual history. Many ethnic groups adopted the pasty for use in the Copper Country copper mines; the Finnish immigrants to the region mistook it for the traditional piiraat and kuuko pastries The pasty has become strongly associated with all cultures in this area, and in the similar Iron Range in northern Minnesota.

Mineral Point, Wisconsin, was the site of the first mineral rush in the USA during the 1830s. After lead was discovered in Mineral Point, many of the early miners migrated from Cornwall to this south-western Wisconsin area. Those Cornish miners brought their skills working in the deep underground tin mines of Cornwall. They also brought their recipe and appetite for the pasty.

The Anthracite regions of northeastern Pennsylvania, including the cities of Wilkes-Barre, Scranton, and Hazleton, had an influx of miners to the area in the 1800s and brought the pasty with them. To this day, pasties are still a local favourite. In 1981, a Pennsylvania entrepreneur started marketing pasties under the brand name Mr. Pastie.

The Mexican state of Hidalgo, and the twin silver mining cities of Pachuca and Real del Monte (Mineral del Monte), have notable Cornish influences from the Cornish miners who settled there, with pasties being considered typical local cuisine. In Mexican Spanish, they are referred to as pastes. The town of Real del Monte in Mexico is the site of a museum of pasties, and the annual International Pasty Festival is held there for three days each October. They are also popular in South Africa, New Zealand and Ulster. 


\section{TPK FINANCIALS}

Toivo's family business has done well over the years, providing both employment opportunities and income for both family members and others. Being relatively frugal in nature, Toivo has retained (and invested, over time) the majority (roughly 50\%) of the annual profits (before taxes) from the business over the past 21 years, and now has a liquid net worth in the low 7 -figure range (say roughly $\$ 4$ million dollars).

The basic recipe for their pasties includes skirt steak (or an equivalent cut of beef), potatoes, onions, rutabaga, and the secret ingredient which provided savory flavor for the pasty - suet, along with salt and pepper. As mentioned earlier, smaller bite-sized versions of the pasty were successfully introduced into the business about 10 years ago, and are called pasty nuggets. Many customers purchase the pasty nuggets as a snack, for use during parties, tailgating at sporting events, and for use as hors d'oeuvres when entertaining.

Currently, on an average day, TPK sells the equivalent of 300 pasties (for calculation purposes note that 10 pasty nuggets $=1$ regular pasty). The store is open approximately 363 days out of the year (closed on Easter and Christmas each year).

The current retail price of each item is as follows: (all data in USD)

Regular pasty: $\$ 5.00$ (tax included, for either with rutabaga or without rutabaga)

Pasty nuggets: $\$ .50$ per nugget (tax included)

Annual gross sales (in \$ dollars) for TPK over the past 20 years are as follows:

$\begin{array}{ll}1996 & \$ 410,000 \\ 1997 & \$ 440,000 \\ 1998 & \$ 470,000 \\ 1999 & \$ 490,000 \\ 2000 & \$ 502,000 \\ 2001 & \$ 490,000 \\ 2002 & \$ 470,000 \\ 2003 & \$ 480,000 \\ 2004 & \$ 490,000 \\ 2005 & \$ 510,000 \\ 2006 & \$ 520,000 \\ 2007 & \$ 530,000 \\ 2008 & \$ 440,000 \\ 2009 & \$ 380,000 \\ 2010 & \$ 390,000 \\ 2011 & \$ 420,000 \\ 2012 & \$ 460,000 \\ 2013 & \$ 510,000 \\ 2014 & \$ 550,000 \\ 2015 & \$ 565,000 \\ 2016 & \$ 602,000\end{array}$

Seasonal variations in sales volume exist (for example, the summer months of May - early September generate a significant level of tourist-based sales), and at times local / regional economic conditions have influenced sales (i.e., during some years the local iron ore mines experienced periodic shutdowns, strikes, and even permanent closures, which had an impact on all local businesses).

Based upon the average price of a regular pasty, the costs of ingredients, labor, etc. to produce a single (regular pasty) was $\$ 1.10$. In addition to this, annual operating expenses for the business (in the most recent year) were $\$ 211,434.79$, 
resulting in an annual profit (before taxes) of $\$ 258,125.21$, which represents a $42.88 \%$ return on sales (again, in the most recent year).

\section{STRATEGIC OPTIONS}

Toivo had been thinking about a wide array of strategic options in order to expand TPK, and wondering about the attractiveness (and potential profitability) of the various approaches.

One idea he had was to add another location (or locations) in the Upper Peninsula of Michigan, focusing on higher traffic areas (one example might be St. Ignace or Mackinaw City, which are major tourist destinations in the summer months for tourists visiting Mackinac Island). Toivo estimates start up costs for one more location in either of these cities would range from (low) $\$ 500 \mathrm{~K}$ to (high) $\$ 1$ million, and was wondering what the break even volume would be in order to cover those start up costs. These locations would probably be open only 4 months out of the year (roughly mid-May through early September). Tourism was growing in the Upper Peninsula of Michigan (due to a lot of positive publicity over recent years) and was an increasingly important part of a lot of local businesses.

A somewhat related idea would be for TPK to follow the "snowbirds" from the upper Midwest region of the U.S., in that many retired "baby boomers" head south for the winter months. Should TPK open up a retail location somewhere in Florida or Arizona, based upon the large number of "snowbirds" that winter in these areas. Toivo thought the start up cost of one store in either of these potential locations would be approximately $50 \%$ higher than his estimates for St. Ignace or Mackinaw City, Michigan.

Toivo had another idea, and that was to sell TPK's product's online. His thinking was that many people were familiar with the pasty, and had in fact visited his store and/or were familiar with this iconic food from their visit(s) to the Upper Peninsula of Michigan. On the downside, shipping costs would eat (pun intended) into profitability, and this would mean Toivo might have to raise prices for product sold online, and/or have a larger minimum order requirement (say 10 regular pasties). Shipping costs (2nd day air, dry ice, styrofoam container) might run $\$ 25.00$ per order, on average, and it would take time, effort, space and much planning to ship orders on a daily basis. Additionally, being able to fulfill orders based upon unpredictable online demand also worried Toivo - might locals not be able to buy pasties on certain days because of a surge in demand.

Another thought that Toivo had come from a visit to Cardiff, Wales which Toivo and his wife had made back in 2001 where they encountered a little pasty shop that had at least 28 different versions of pasties. Should TPK develop a line of specialty pasties and what would the impact be on sales? Would any cannibalization of existing "regular" pasty sales occur if pasties with different meats, vegetables, etc. were also offered? On a related note, Toivo though pasty nuggets seemed like an example of this line of thinking, and the introduction of the pasty nugget had been quite successful, as they now represent about one-third of annual sales (in $\$$ dollars).

Still another idea that Toivo had entertained periodically was to somehow further develop the TPK brand and then solicit offers from a larger food company who would have the financial and marketing resources to further develop the brand and then distribute the product regionally and maybe even nationally. Toivo noted that many small food companies have done this - started very small (local) and gradually expanded regionally and nationally, but wondered what the success rate was? Also, what about product quality (i.e., is a frozen pasty as good as a fresh pasty)? Maybe pasty nuggets would be a good "snack food" vehicle for expansion of the brand. Maybe Toivo should approach a regional grocery store chain to strike up a distribution agreement using their retail stores (as a starting point for this strategic option). If Toivo sold TPK, LLC to a larger company, what would be a "fair" price for the company the TPK brand?

Lastly, Toivo also thought about the old saying "if it ain't broke don't fix it" and perhaps just maintaining the current company strategy and operations is the best way to go. TPK is quite profitable, and provides employment opportunities and financial rewards for both family members and others in the community. The business is also a source of pride for Toivo and his family (deep down, Toivo likes being known as "The Pasty King"). Perhaps some other options exist that Toivo hadn't thought of yet, though. 


\section{CONCLUSION}

For each / all of these options, Toivo wondered about the impact on sales (\$), profits, and what was the level of risk; should he develop some further analysis of each of these strategic options, looking at the qualitative advantages and disadvantages associated with each strategic option, coupled with some quantitative analysis (again) for each strategic option? Which one of these strategic options had the most growth potential, and why? What was the best overall approach?

As Toivo was thinking about these issues, he also wondered when he would find the time to do all of this analysis. Just then the bell on the front door of the shop rang again, and Toivo left the kitchen area to greet the next customer another local - to which he said "with or without?". Would the future of TPK be "with or without" expansion, and if so, what form of expansion? Toivo had a lot to think about.

\section{TEACHING NOTE}

This case can be used in a variety of classroom settings, including an introductory marketing course, introduction to business course, entrepreneurship course, or as a case early in a course related to marketing strategy or marketing management. Students, working individually or in teams, can be assigned the possible case teaching questions discussed below. The case is a good example of how a small company may consider expansion plans, and uses basic analyses including unit and $\$$ dollar break even, unit and \$ sales estimates, etc..

It should also be noted that TPK is a fictitious company, but the issues and examples used in the case reflect a range of research and experiences developed by the case author over time. Any questions regarding the case can be directed to gbrunswi@nmu.edu.

\section{Possible Case Teaching Questions:}

1. Comment on how profitable is this business in the most recent year of operation in the case (2016)? How profitable has TPK been over the past 20 years? Is this company in a good position to consider expansion? Why or why not?

The case states that in 2016, gross sales were $\$ 602,000$ (all financial data is in USD), and annual operating expenses were $\$ 211,434.79$. Pasties retail for $\$ 5.00$ and the cost to produce a pasty is $\$ 1.10$, meaning the gross margin $\%$ for the business (on average) is 78\% (and the cost of goods sold is $22 \%$ ). $\$ 602,000 \times .78=\$ 469,560$, which represents the gross profit for 2016, minutes the annual operating expenses given in the case for $2016(\$ 211,434.79)$ equals $\$$ $258,125.21$, or a $42.88 \%$ return on sales ( $\$ 258125.21$ divided by $\$ 602,000=42.88 \%$ rounded up).

Based upon the gross margin and cost of goods sold data, students could be asked to prepare a spreadsheet showing how profitable the business has been over the past 20 some years, and then comment on the data. Clearly a $42.88 \%$ return on sales is respectable, and the business must have some retained profits (over the years) to fund possible expansion (as several ideas are discussed in the case). Assuming a $42.88 \%$ return on sales, here are the results for the past 20 years:

$\begin{array}{ll}1996 & \$ 410,000 \times .4288=\$ 175,808.00 \\ 1997 & \$ 440,000 \times .4288=\$ 188,672.00 \\ 1998 & \$ 470,000 \times .4288=\$ 201,536.00 \\ 1999 & \$ 490,000 \times .4288=\$ 210,112.00 \\ 2000 & \$ 502,000 \times .4288=\$ 215,257.60 \\ 2001 & \$ 490,000 \times .4288=\$ 210,112.00 \\ 2002 & \$ 470,000 \times .4288=\$ 201,536.00 \\ 2003 & \$ 480,000 \times .4288=\$ 205,824.00 \\ 2004 & \$ 490,000 \times .4288=\$ 210,112.00 \\ 2005 & \$ 510,000 \times .4288=\$ 218,688.00 \\ 2006 & \$ 520,000 \times .4288=\$ 222,976.00\end{array}$




$\begin{array}{ll}2007 & \$ 530,000 \times .4288=\$ 227,264.00 \\ 2008 & \$ 440,000 \times .4288=\$ 188,672.00 \\ 2009 & \$ 380,000 \times .4288=\$ 162,944.00 \\ 2010 & \$ 390,000 \times .4288=\$ 167,232.00 \\ 2011 & \$ 420,000 \times .4288=\$ 180,096.00 \\ 2012 & \$ 460,000 \times .4288=\$ 197,248.00 \\ 2013 & \$ 510,000 \times .4288=\$ 218,688.00 \\ 2014 & \$ 550,000 \times .4288=\$ 235,840.00 \\ 2015 & \$ 565,000 \times .4288=\$ 242,272.00 \\ 2016 & \$ 602,000 \times .4288=\$ 258,137.60\end{array}$

Total \$ annual sales 1996 through $2016(21$ years $)=\$ 10,119,000.00$

Average $\$$ annual sales 1996 through $2016(21$ years $)=\$ 481,857.14$

Total \$ annual profit before taxes 1996 through $2016(21$ years $)=\$ 4,339,027.20$

Average \$ annual profit before taxes 1996 through 2016 (21 years) $=\$ 206,620.34$

Note that these averages could be used in future analyses mentioned below, when evaluating the various growth options or modes being considered by TPK.

\section{Evaluate the pros and cons of TPK's possible expansion plans, in general.}

A wide array of expansion options exist for TPK (which will be discussed at greater length in a later question), but the core question is an interesting one for students to ponder. TPK is currently a highly profitable business, one that brings financial benefits and job satisfaction to Toivo Maki, his family and his employees. Does the company want to change their current status, and take on more risk (and incur more stress)? Will quality of the product (and/or customer relationships) be negatively impacted by future expansion? Can Toivo successfully manage another business (if more than 1 store is developed)? Can Toivo relinquish control to others? On the other hand, given the high (average) level of return on sales, it would take approximately $\$ 2,368,097.00$ in gross sales (about $4 \mathrm{x}$ the current level of gross sales) in order for TPK to generate $\$ 1,000,000$ in annual profit (before taxes), and it seems reasonable for TPK to increase sales by multiples ( $2 \mathrm{x}$, maybe $3 \mathrm{x}$ ) over time, given the appropriate mode of expansion.

3. Consider the pros and cons of each of the following options for TPK: Add another location, sell pasties online, position the company to be sold to a larger firm, and / or selling pasties in grocery stores regionally. Which option would you select and why?

Students could be asked to look at both the qualitative pros and cons of each possible mode of expansion, and also should do some rudimentary quantitative analysis for each (with some reasonable assumptions being made for certain modes of expansion).

Starting with opening another location, the current gross margin \% for TPK is $78 \%$ (or $\$ 3.90$ on a $\$ 5.00$ retail price per pasty), and Toivo estimates it will take $\$ 500 \mathrm{~K}$ to $\$ 1,000,000$ to open a new store location in a higher traffic (tourist) area such as St Ignance or Mackinaw City. Students could use the two investment endpoints ( $\$ 500 \mathrm{~K}$ or $\$ 1$ million) or an average of the two $(\$ 750 \mathrm{~K})$ in order to calculate a break-even point for this option.

$\$ 500 \mathrm{~K} / \$ 3.90=128,206$ pasties (unit break even) $x \$ 5.00=\$ 641,030$ ( $\$$ dollar break even) $\$ 750 \mathrm{~K} / \$ 3.90=192,308$ pasties (unit break even) $\mathrm{x} \$ 5.00=\$ 961,540$ ( $\$$ dollar break even) $\$ 1$ million $/ \$ 3.90=256,411$ pasties (unit break even) $\mathrm{x} \$ 5.00=\$ 1,282,055$ ( $\$$ dollar break even)

It should be clear to students that if Toivo choses this option, the $\$ 500 \mathrm{~K}$ investment level seems plausible, while the $\$ 750 \mathrm{~K}$ and $\$ 1$ mill levels seem more risky, given the company's current level of sales (i.e., it would seem that 
surpassing the existing $\$$ sales at a new location in the first year of operation would be optimistic, while matching current $\$$ sales seems more reasonable).

Another way to look at opening another store would be asking the question "how many pasties might a new store sell, per day, on average, in a tourist area"? The current store sells 300 pasties per day, on average, but it is noted that the summer months have higher sales levels due to tourism. Assume that a tourist oriented location would have 120 days of tourist traffic (say May through August) where the level of sales would be 2x or 3x the normal level; this would equate to $72,000(2 \mathrm{x})$ or $108,000(3 \mathrm{x})$ just for that 120 day period. Per the previous analysis, break even at the $\$ 500 \mathrm{~K}$ investment level for a new store is 128,206 pasties, which is close to the $3 \mathrm{x}$ level of 108,000. Assuming a new location would be open year round (and would serve tourists and locals alike), it seems quite plausible that enough pasties would be sold in order to easily cover the breakeven point for the lower level of investment (and maybe the middle and higher levels also).

Looking at selling pasties online might also be an interesting option for TPK to pursue. A whole range of additional costs would be incurred in pursing this mode of expansion, and students should be asked to consider (first) what those costs would be:

- Establishing and maintaining a website

- Search engine optimization / web advertising

- Additional fulfillment costs

- As a starting point some reasonable assumptions might be made regarding these costs:

- Establishing and maintaining a website $=\$ 12 \mathrm{~K}$ per year

- Search engine optimization / web advertising $=\$ 24 \mathrm{~K}$ per year

- $\quad$ Additional fulfillment costs $=.50$ per pasty sold + one new employee $(\$ 30 \mathrm{~K}$ per year $)$

These assumptions could be further discussed and varied (using a what-if analysis), but starting with these assumptions a basic analysis should be performed:

$\$ 66 \mathrm{~K}(12+24+30) / \$ 3.4(\$ 3.90-.50)=19,412$ (unit break even) $\mathrm{x} \$ 5.00=\$ 97,060$ ( $\$$ break even).

Both the unit and $\$$ dollar break even seem quite reasonable, but some additional considerations should be taken into account. First, who would pay the shipping for the pasties (which would be frozen when shipped, but would still require a specialized container (hence the .50 additional fulfillment costs per pasty) and $2^{\text {nd }}$ day air delivery services)). If TPK pays for the shipping, this will significantly reduce the profitability of this option (and raise the break even points). If TPK has to be $\$ 20$ shipping per order (say a minimum order of 10 pasties), what will this do to their profitability? Should a minimum order size be required (10 pasties minimum)? Should free shipping be offered for first-time buyers (or larger orders of say 30 or more pasties)? Secondly, will selling pasties online cannibalize any of the existing sales for TPK? While it is unlikely that this would be significant, students might consider the impact of a $5-10 \%$ reduction in sales, in conjunction with an estimate of how many pasties would be ordered online each day (and then develop an estimate for first year sales).

Positioning the company (TPK) to be sold to a larger firm is another option to consider. From a quantitative perspective, students should be able find information on how to do this via the web; for example:

https://www.calcxml.com/calculators/business-valuation

Another more rudimentary approach might be to use a multiplier (3x, 4x, 5x, as examples) based upon annual profits before taxes, as an estimate of the resale value of the firm. Based upon the most recent year, these would be the suggested values at $3 \mathrm{x}$ to $5 \mathrm{x}$ :

$3 \times \$ 258,125.21=\$ 774,375.63$
$4 \times \$ 258,125.21=\$ 1,032,500.84$
$5 \times \$ 258,125.21=\$ 1,290,626.05$

Copyright by author(s); $\underline{\mathrm{CC}-\mathrm{BY}}$ 
Using the 21 year average of annual profits before taxes ( $\$ 206,620.34$, as calculated earlier), here are the comparable values:

$$
\begin{aligned}
& 3 \times \$ 206,620.34=\$ 619,861.02 \\
& 4 \times \$ 206,620.34=\$ 826,481.36 \\
& 5 \times \$ 206,620.34=\$ 1,033,101.70
\end{aligned}
$$

Some discussion regarding the hard assets (building, equipment) as well as the value of the brand equity (TPK brand name) might also be introduced into the analysis.

From a qualitative perspective, students should be asked to discuss this option from Toivo's perspective, asking themselves if they (students) owned this business, would they want to sell, and if so why (or why not)? If they decide to sell, what would they do afterwards (retire, start another business, etc.)? In the end, this option is only viable if Tovio wants to sell, can find a buyer, and they and they can both agree upon a reasonable price.

Lastly, selling pasties in grocery stores regionally should also be considered. Frozen versions of the pasty and pasty nugget products could initially be distributed regionally if TPK can work with food brokers or larger grocery retailers in order to obtain distribution. This might result in additional investments required by TPK in order to increase their production capabilities (similar to the earlier analysis, students might consider investing $\$ 500 \mathrm{~K}$ to $\$ 1$ million for this option). Another key consideration here would be the reduced gross margins if TPK sells frozen products in grocery stores.

Assuming the following:

- $\$ 5.00$ retail price for a frozen pasty in a grocery store

- $\$ 1.10$ retailer markup of $22 \%$

- $\$ 3.90$ wholesale price

- $\$ .273$ broker commission (7\%)

- $\$ 3.627$ manufacturer's price for TPK

- $\$ 1.10$ cost of goods sold or cost to manufacturer for TPK

- $\$ 2.527$ gross profit per pasty for TPK

Students should be asked to calculate break even based upon this lower profitability.

$$
\begin{aligned}
& \$ 500 \mathrm{~K} / \$ 2.527=197,864 \text { (unit break even) } x \$ 3.627=\$ 717,652.73(\$ \text { dollar break even) } \\
& \$ 750 \mathrm{~K} / \$ 2.527=296,795 \text { (unit break even) } \times \$ 3.627=\$ 1,076,475.46 \text { ( } \$ \text { dollar break even) } \\
& \$ 1 \text { million } / \$ 2.527=395,727 \text { (unit break even) x } 3.627=\$ 1,435,301.83 \text { ( } \$ \text { dollar break even) }
\end{aligned}
$$

Students should consider the possible incremental level of sales generated by selling frozen pasties in stores; for example, if distribution in 100 stores was achieved regionally, at the $\$ 500 \mathrm{~K}$ investment level this would mean that each store would need to sell about 1,979 pasties (per year) in order to achieve break even, or about 5 per day (assuming the store is open 365 days per year). As a snack food, the pasty nugget products could be emphasized in retail stores, but this might require some investment in advertising and sales promotion (which again could be taken into account through student's analysis of this option - for example a promotional budget of say $\$ 200 \mathrm{~K}$ could be suggested, and then factored into the break-even analysis for this option).

On the other hand, cannibalization is a more serious concern with this option, especially closer to TPK's existing store. Students should consider, again, the impact of a $5-10 \%$ reduction in existing sales along with this option.

4. Pick one of the expansion modes or options identified in the case (i.e., add another location, sell pasties online, position the company to be sold to a larger firm, and / or sell pasties in grocery stores regionally) and prepare a defense for that growth option. 
Students individually, or in teams, could prepare a brief presentation for the rest of the class to argue for their selected or assigned expansion mode or option. The faculty member could also introduce additional expansion modes or options into the discussion at this point, and/or could change some of the key financial assumptions in the case (i.e., the gross margin $\%$, various costs, etc.).

\section{AUTHOR BIOGRAPHY}

Gary J. Brunswick holds a Ph.D. in Business Administration from Arizona State University, and currently holds the rank of Professor of Marketing at Northern Michigan University. His research interests include marketing strategy, services marketing and e-commerce. His research has been published in a range of journals, including the Journal of the Academy of Marketing Science, Journal of Consumer Behaviour, The Marketing Management Journal, The Journal of Professional Services Marketing, The Journal of Business and Economics Research, The International Journal of Case Studies and Research, The Journal of the International Academy of Case Studies, The Academy of Educational Leadership Journal and The Academy of Marketing Studies Journal. Email: gbrunswi@nmu.edu

\section{REFERENCES}

https://whttps://en.wikipedia.org/wiki/Pasty

https://www.calcxml.com/calculators/business-valuation https://www.webpagefx.com/marketing-calculator.html https://www.marketingforsuccess.com/marketing-calculator/ 


\section{NOTES}

